\title{
Globalização, neoliberalismo e universidade: algumas considerações
}

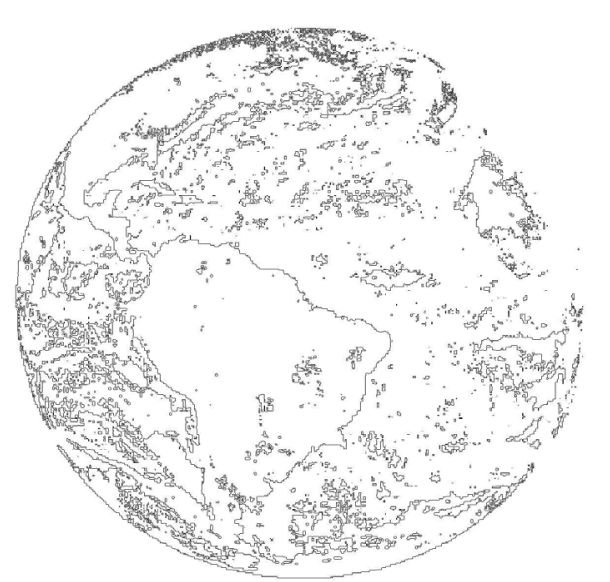

\author{
Marília Freitas de Campos Pires ${ }^{1}$ \\ José Roberto Tozoni Reis ${ }^{2}$
}

PIRES, M. F. C.; REIS, J. R. T. Globalization, neo-liberalism and universities: a few considerations. Interface Comunicação, Saúde, Educação, v.3, n.4, 1999.

This article presents the main signs of the globalization process as well as the basic principles of the neo-liberal project currently being developed all over the world, and assesses the consequences of the subordination of a peripheral economy to the interests of international capital. The process of economic globalization and the progress of neo-liberal ideas impose upon Brazilian society the transformation of public education and health-care services, turning them into vehicles for the private accumulation of capital. This occasionally takes place in a disguised manner, worsening the quality of life of the bulk of the population.

KEY WORDS: urban reform, organization and administration, social policy.

Este artigo apresenta as principais marcas do processo de globalização e os princípios básicos do projeto neoliberal em desenvolvimento no mundo atual e considera as conseqüências da subordinação de uma economia periférica aos interesses do capital internacional. O processo de globalização da economia e o avanço das idéias neoliberais impõem à sociedade brasileira a transformação dos serviços públicos de educação e saúde em meios de acumulação privada de capital, algumas vezes de forma dissimulada, em prejuízo das condições de vida da maioria da população.

PALAVRAS-CHAVE: Reforma urbana, organização E administração, política social.

${ }^{1}$ Professora do Departamento de Educação do Instituto de Biociências de Botucatu - Unesp/SP.

${ }^{2}$ Professor do Departamento de Neurologia e Psiquiatria da Faculdade de Medicina de Botucatu - Unesp/SP.

fevereiro, 1999 
Ouvimos, hoje, em todos os setores da vida social, falar de uma nova ordem mundial. A conjunção de uma crescente internacionalização $e$ interdependência dos mercados com a formação de áreas de livre comércio e a chamada Terceira Revolução Tecnológica caracterizam atualmente a globalização da economia. A globalização tem aparecido como uma nova diretriz para a organização da economia dos mais diferentes países do mundo, atingindo todos os setores da organização social. As metáforas da globalização estão por aí (Ianni, 1997): fim do Estado, fim da Geografia, fim da História, mundialização, aldeia global, mercado único etc. No entanto é preciso lembrar que o capitalismo sempre foi internacional.

O movimento de expansão é uma tendência inerente ao capitalismo. Já em 1848 Marx e Engels, no Manifesto do Partido Comunista, entre outros escritos, apontavam a tendência à expansão do capitalismo como uma característica deste modo de organização da produção:

...Essa revolução contínua da produção, esse abalo constante de todo o sistema social, essa agitação permanente e essa falta de segurança distinguem a época burguesa de todas as precedentes. Dissolvem-se todas as relações sociais antigas e cristalizadas, com seu cortejo de concepções e de idéias secularmente veneradas; as relações que as substituem tornam-se antiquadas antes de se ossificar. Tudo que era sólido e estável se esfuma, tudo o que era sagrado é profanado, e os homens são obrigados finalmente a encarar com seriedade suas condições de existência e suas relações recíprocas.

Impelida pela necessidade de mercados sempre novos, a burguesia invade todo o globo. Necessita estabelecer-se em toda parte, explorar em toda parte, criar vínculos em toda parte.

Pela exploração do mercado mundial a burguesia imprime um caráter cosmopolita à produção e ao consumo em todos os países. Para desespero dos reacionários, ela retirou à indústria sua base nacional. As velhas indústrias nacionais foram destruídas e continuam a sê-lo diariamente. São suplantadas por novas indústrias, cuja introdução se torna uma questão vital para todas as nações civilizadas, indústrias que não empregam mais matériasprimas autóctones, mas sim matérias-primas vindas de regiões mais distantes, e cujos produtos se consomem não somente no próprio país mas em todas as partes do globo. Em lugar das antigas necessidades, satisfeitas pelos produtos nacionais, nascem novas necessidades, que reclamam, para sua satisfação, os produtos das regiões mais longínquas e dos climas mais diversos. Em lugar do antigo isolamento de regiões e nações que se bastavam a si próprias, desenvolve-se um intercâmbio universal, uma universal interdependência das nações. E isto se refere tanto à produção material como à produção intelectual. As criações intelectuais de uma nação tornam-se propriedade comum de todas. A estreiteza e o exclusivismo nacionais tornam-se cada vez mais impossíveis; das inúmeras literaturas nacionais e locais, nasce uma literatura universal (Marx \& Engels, 1968, p.26-7). 
Então a tendência à expansão, à globalização, acompanha o capitalismo desde que este modo de produção substituiu o modo de produção da velha sociedade. A vontade de construir uma sociedade global, racional $e$ harmônica está presente no Iluminismo que sustenta, idealmente, a sociedade capitalista já na sua origem. Então o movimento de expansão é uma característica de sua trajetória em busca de sua finalidade, de sua plena realização e seu estado atual explicita esta tendência histórica.

No entanto, a globalização pode ser entendida também como uma nova modalidade de acumulação de capital. Em momentos anteriores a principal estratégia de acumulação capitalista concentrava-se na extensão da produção de valor e de mais valia. Nesta nova modalidade da acumulação, a apropriação de riquezas é resultado, principalmente, de atividades especulativas do mercado financeiro.

Este atual momento de expansão do capitalismo tem algumas marcas específicas. A aceleração da automação da produção somada à agilização dos processos de comunicação, os quais possibilitam afetar de forma imediata o mercado financeiro, permitem a troca não de mercadoria, nem de moeda física, mas de informação. O que caracteriza mais claramente o processo de globalização é a revolução tecnológica informacional. Não há, a rigor, troca de mercadorias nem de papel moeda; há, sim, troca de informações sobre dinheiro, há troca de informações sobre papéis que significam dinheiro. Há uma grande abstração da troca.

Uma outra marca do estágio do capitalismo atual, globalizado, diz respeito à hegemonia das idéias neoliberais. A dimensão político-ideológica deste atual momento do capitalismo é a associação globalização/ neoliberalismo, apresentada como a ante-sala da realização do sonho iluminista de uma sociedade harmônica e racional.

A proposta política neoliberal tem origem na crise teórica, política $e$ econômica do socialismo real e do capitalismo internacional. Essas crises evidenciaram a necessidade de reorganizar o modo de produção capitalista. O modelo neoliberal implantado nos países capitalistas avançados expandese por toda parte (Anderson, 1995). O que aqui se coloca, segundo Anderson, vai além dos aspectos econômicos que parecem predominar nessa discussão; sua expansão pode ser por ora compreendida como um fenômeno internacional de enorme importância:

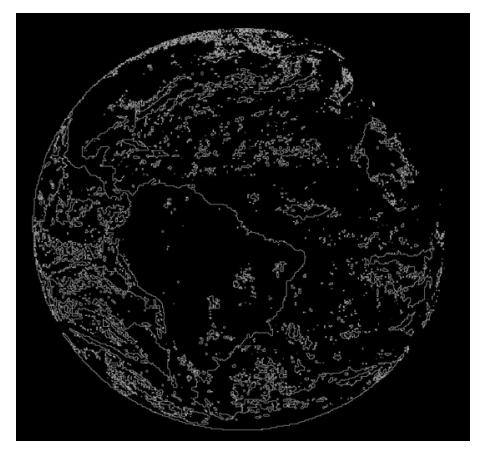

Neste sentido, qualquer balanço atual do neoliberalismo só pode ser provisório. Este é um movimento ainda inacabado. Por enquanto, porém, é possível dar um veredicto acerca de sua atuação durante quase 15 anos nos países mais ricos do mundo, a única área onde seus frutos parecem, podemos dizer assim, maduros. Economicamente, o neoliberalismo fracassou, não conseguiu nenhuma revitalização básica do capitalismo avançado. Socialmente, ao contrário, o neoliberalismo conseguiu muitos dos seus objetivos, criando sociedades marcadamente mais desiguais, embora não tão desestatizadas como queria. Política $e$ ideologicamente, todavia, o neoliberalismo alcançou êxito num grau com o qual seus fundadores originalmente jamais sonharam, 
disseminando a simples idéia de que não há alternativas para os seus princípios, que todos, seja confessando ou negando, têm de adaptar-se a suas normas (Anderson, 1995, p.22-3).

O neoliberalismo é a retomada de alguns princípios do capitalismo liberal do século XIX. É a reação teórica e política veemente contra o Estado intervencionista e de bem estar (Anderson, 1995) que se instalou em alguns países no pós guerra, influenciado pela Revolução Soviética em 1917. É a busca de uma política econômica que vigore sem qualquer limitação dos mecanismos do mercado. Friedrich Hayek foi seu principal pensador, com $O$ Caminho da Servidão, publicado pela primeira vez em 1944. Hayek (1990) coloca-se veementemente contra o Estado Previdenciário, argumentando que este tipo de organização da sociedade abate a iniciativa individual que produz a riqueza, da qual toda sociedade se beneficia a médio e a longo prazo. Neste sentido, a desigualdade social é um valor positivo para gerar e manter o desenvolvimento econômico. A desigualdade é importante para a prosperidade, e a concentração de riquezas beneficia toda a sociedade. Esta alternativa ao Estado Previdenciário pode ser entendida principalmente pelo seu descomprometimento com as políticas públicas econômicas e sociais, pela tentativa de implantação do Estado mínimo. Do ponto de vista conjuntural, esta proposta surgiu para o enfrentamento da crise financeira do modelo de Estado Social - Democrata. Esta reestruturação global do capitalismo elegeu o mercado como o grande regulador econômico e social. A moeda estável, a concentração de riquezas, a contenção de gastos com as funções sociais do Estado, o combate ao sindicalismo e a taxa natural de desemprego são traços e, ao mesmo tempo, metas do ideário neoliberal:

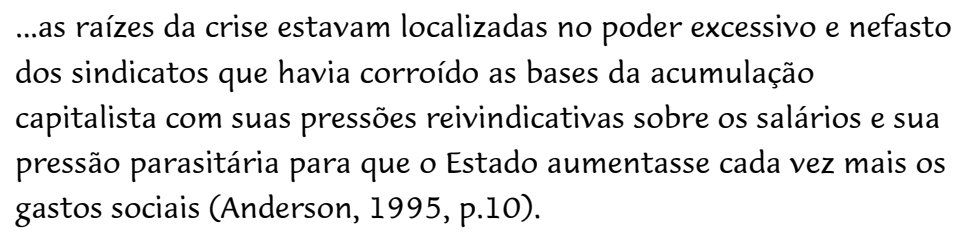

A reação contra o Estado intervencionista e o Estado de bem-estar social $e$ a busca do Estado mínimo, emergiram também da crise fiscal do Estado. No entanto, Estado mínimo não significa Estado fraco. O modelo do Estado forte mas desobrigado socialmente é o que se pode chamar da síntese do neoliberalismo (Anderson, 1995). O Estado forte intervém na economia não mais como regulador das relações sociais, mas principalmente para possibilitar o modelo de acumulação

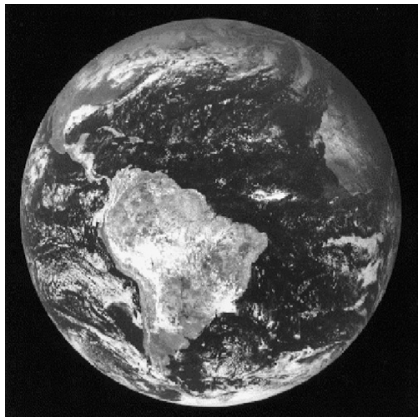
neoliberal, que hoje privilegia o capital financeiro. ${ }^{3}$

A atual etapa do capitalismo tem caráter extremamente competitivo (Therborn, 1995) e, em sua reestruturação global, situa o mercado como grande regulador econômico (Santos, 1995; Moraes \& Duayer, 1995). O Estado tem que ser suficientemente forte para impor políticas que favoreçam a acumulação especulativa, o que necessariamente aumenta o desemprego e a crise.
${ }^{3} \mathrm{O}$ recente ajuste fiscal imposto pelo FMI ao Brasil, no enfrentamento da crise no segundo semestre de 1998, expressa este modelo de organização do Estado. O setor público teve, no primeiro semestre de 1998, um superávit primário de meio bilhão de reais, isto é, gastou em atividades próprias do Estado menos do que arrecadou. No entanto, ao pagar 33 bilhões de reais de juros aos grandes bancos, operou um déficit nominal de 32,5 bilhões de reais com previsão de aumento até o final do ano, em função do aumento das taxas de juros. O Estado então intervém na economia em sua dimensão financeira. $\mathrm{O}$ pagamento de juros para 1999 necessitará de mais de 25 bilhões de dólares que serão gerados, segundo diretrizes do FMI, com aumento de impostos e cortes de gastos em todos os setores dos serviços públicos.

(Folha de São Paulo, (11/09/98), 
A desregulamentação da economia, pelo Estado, é fundamental para a implantação desse modelo econômico em todo o mundo. Desde o fim da década de setenta e principalmente nas décadas de oitenta e noventa, o neoliberalismo vem se expandindo. Já no Manifesto encontrávamos a relação entre expansão e dominação (Lowy, 1998). Hoje, mais do que então, assistimos ao capital dominando o mundo. O capitalismo é um processo simultaneamente social, econômico e cultural e seu desenvolvimento é desigual e contraditório (Ianni, 1997). O capital exerce um poder ilimitado sobre todo o mundo. As regras do mercado livre e do lucro capitalista controlam todas as esferas da vida humana (Lowy, 1998) Margareth Thatcher na Inglaterra, Reagan nos USA, Khol na Alemanha, entre outros, defenderam políticas neoliberais e de desregulamentação implantadas pelo G-7 e FMI consolidando, nos anos noventa, o atual regime de acumulação de capital.

Para o neoliberalismo, a receita para recuperar o crescimento passa pela estabilização da moeda, contendo os gastos com o bem estar social, pela reforma fiscal que concentra riquezas, e com isso possibilita novos investimentos e também pela restauração de uma taxa "natural" de desemprego. O desemprego em massa produzido pelo neoliberalismo em todas as partes do mundo é o componente mais perverso da nova ordem. Partindo do pressuposto de que só o capital concentrado cria riquezas, isto é, aumento de capital significa investimentos, o desemprego, ou melhor, a taxa natural de desemprego, que faz diminuir os salários, garante maior taxa de lucro e, portanto, maior acumulação de capital. Desta forma o desemprego não é uma conseqüência indesejada da economia neoliberal, mas um de seus componentes estratégicos.

A utopia da construção do homem pleno pela organização social do trabalho, contida nos escritos de Marx e Engels, pode ainda ser alcançada? Nesta lógica, o domínio da natureza permitiria aos homens a produção dos bens necessários para a vida em menos tempo de trabalho, pelo desenvolvimento tecnológico, liberando parte da vida para o desenvolvimento humano. Estaríamos então perto desta utopia com o desenvolvimento tecnológico que alcançamos neste final de século? $\mathrm{O}$ avanço tecnológico hoje permite a realização desta utopia? Não no capitalismo, que se apropria da tecnologia não para liberar - ou libertar - os homens, mas para racionalizar a produção, dispensando o trabalhador com o objetivo de se expandir e concentrar capital. A solução neoliberal para o avanço tecnológico é jogar fora parte da força de trabalho para manter um excedente de reserva que permita manter a concentração, pela taxa de lucro cada vez maior.

A globalização da economia, sob o neoliberalismo, atualmente produz o terror pela ameaça do desemprego para os ainda empregados, e a crescente exclusão econômica e social da maioria da população. A desigualdade social é cada vez maior e fica ainda mais evidente quando identificamos a efetiva participação dos países no processo de globalização da economia. Touraine (1995) apresenta dados para explicitar esta situação: $20 \%$ da população dos países ricos ficam fora do processo, $50 \%$ na América Latina e $80 \%$ na África. Desemprego, desigualdade, exclusão social e exploração compõem o cenário 
sócio-político atual.

Depois da exploração do homem pelo homem em nome do capital, o neoliberalismo e seu braço operacional, que é a globalização, criaram, mantêm e ampliam, em nome da sacralidade do mercado, a exclusão de grande parte do gênero humano. O próximo passo será a eliminação? Caminhamos para um holocausto universal, quando a economia modernizada terá repugnância de custear a sobrevivência de quatro quintos da população mundial? Depois de explorados e excluídos, bilhões de seres humanos, considerados supérfluos, devem ser exterminados?

O raciocínio é bem mais do que uma hipótese. É um desdobramento lógico do horror econômico fabricado no laboratório dos economistas neste final de século. Horror - este sim - globalizado pelos governos que buscam resultados contábeis e condenam a ação social como jurássica.

A massa dos excluídos em todo o mundo constituirá um formidável dinossauro que a economia modernizada eliminará como inviável no Estado neoliberal. Não se trata de um

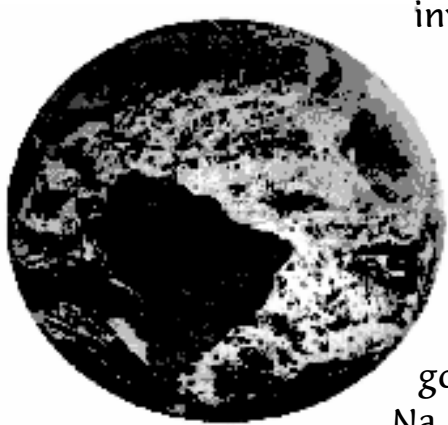
apocalipse, mas de um novo eixo da história. Só os melhores, os economicamente arianos, deverão sobreviver. Os não arianos formarão o gueto - e como a manutenção do gueto é um paradoxo econômico (para que produzir para quem não pode produzir?), a solução a médio ou a longo prazo será o extermínio em massa.

Menos custo e mais benefício para os balanços de governos e empresas (Cony, 1997, $2^{\text {a }}$ capa).

Na reestruturação do capitalismo, o avanço tecnológico e a automação se apresentam como características dos atuais processos de produção, e são elementos reestruturadores das relações de trabalho. Antunes (1995), discutindo as metamorfoses no mundo do trabalho, situa a discussão da reestruturação como um processo mais complexo $e$ contraditório do que o apresentado pelos defensores do neoliberalismo e da nova organização do trabalho e das sociedades. Neste sentido afirma:

...de um lado verificou-se uma desproletarização do trabalho industrial, fabril, nos países de capitalismo avançado, com maior ou menor repercussão em áreas industrializadas do Terceiro Mundo. Em outras palavras, houve uma diminuição da classe operária industrial tradicional. Mas, paralelamente, efetivou-se uma expressiva expansão do trabalho assalariado, a partir da enorme ampliação do assalariamento no setor de serviços; verificou-se uma significativa heterogeneização do trabalho, expressa também através da crescente incorporação do contingente feminino no mundo operário; vivencia-se também subproletarização intensificada, presente na expansão do trabalho parcial, temporário, precário, subcontratado, "terceirizado", que marca a sociedade dual no capitalismo avançado, da qual os gastarbeiters na Alemanha e o laboro nero na Itália são exemplos do enorme contingente de trabalho imigrante que se dirige para o chamado Primeiro Mundo, em busca do que ainda permanece do welfare 
state, invertendo o fluxo migratório de décadas anteriores, que era do centro para a periferia (Antunes, 1995, p.41).

Estas contradições confirmam a desigualdade entre os homens e entre as sociedades. Neste cenário de reestruturação "parcial” das relações de trabalho, aparece a especialização multifuncional (exigida principalmente pela automação dos processos de produção). A economia mundial, com suas enormes diferenças, tende a exigir trabalhadores qualificados, com nova base técnica e cultural (Dowbor, 1994). Esta exigência, somada ao desemprego estrutural que atinge diariamente todos os países do mundo, inclusive os países de maior estabilidade econômica nos quais o neoliberalismo vem se instalando, traz para as relações de trabalho a competitividade. Kurz (1996) afirma que:

\footnotetext{
Nos anos 80 e 90, a base desse desemprego estrutural, de ciclo para ciclo, tornou-se cada vez maior em quase todos os países; em 1995, segundo números da Organização Internacional do Trabalho, 30\% da população economicamente ativa de todo o mundo não possuíam emprego estável (Kurz, 1996, p.14).
}

O desenvolvimento tecnológico que permitiria o aumento da produtividade sem diminuir o número de empregos não encontra espaço no processo de globalização capitaneado pelo neoliberalismo. A lógica da produção moderna, cujo objetivo principal e praticamente único é originar lucro privado, cria uma situação paradoxal:

É por isso que, na história econômica moderna, a jornada de trabalho diminuiu numa proporção muito menor do que o aumento correspondente de produtividade. Hoje em dia, os assalariados ainda trabalham mais e durante mais tempo do que os camponeses da Idade Média.

A diminuição dos custos, portanto, não significa que os trabalhadores trabalham menos mantendo a mesma produção, mas que menos trabalhadores produzem mais produtos. $\mathrm{O}$ aumento da produtividade reparte seus frutos de forma extremamente desigual: enquanto trabalhadores "supérfluos" são demitidos, crescem os lucros dos empresários. Mas, se todas as empresas entrarem nesse processo, há a ameaça de surgir um efeito com o qual não contavam os interesses obtusos da economia empresarial: com o crescente desemprego, diminui o poder de compra da sociedade. Quem comprará então a quantidade cada vez maior de mercadorias? (Kurz, 1996, p.14).

O desemprego pode vir a ser o limite na expansão do mercado, criando este absurdo paradoxo (destruir o potencial de consumo da enorme massa de desempregados) que o capitalismo vai ter que enfrentar.

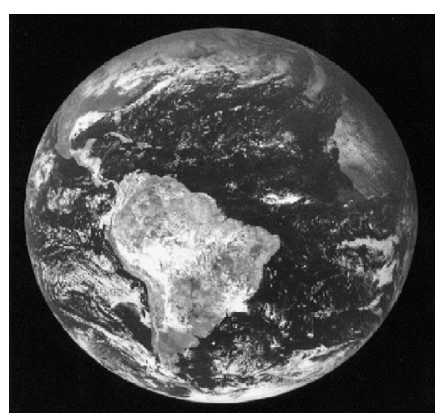


De qualquer maneira, a produtividade como meta, e talvez como mito, difunde nas sociedades modernas a busca da qualidade total em todos os seus níveis de organização.

A desregulamentação da economia e as idéias neoliberais no Brasil tomaram corpo no início dos anos noventa. No entanto, foi durante a ditadura militar que começou o processo de dilapidação do Estado, especialmente no que diz respeito aos serviços públicos que garantem direitos sociais, transformando os serviços de educação e de saúde, entre outros, em meios de acumulação de capital. Sua principal estratégia foi a deterioração destes serviços e o financiamento do capital privado, criando, desta forma, condições políticas para o aparecimento da ideologia neoliberal. No governo Collor, o discurso político, inclusive eleitoral, elegeu inicialmente o Estado Empresário como vilão, afirmando ser necessário privatizar as empresas estatais tidas como deficitárias e sugadoras de recursos, para poder garantir as políticas públicas de saúde, educação, assistência social etc. Assim, no discurso - e só no discurso - as propostas de privatização das empresas estatais foram usadas como forma de garantir o Estado de bemestar-social, camuflando o projeto neoliberal em curso. Naquele momento, a ofensiva liberal ainda encontrou alguma resistência por parte da sociedade civil, mas a ameaça de hiperinflação no início do governo Itamar criou as condições definitivas para a implantação de uma política mais acentuadamente neoliberal do presidente (agora reeleito) Fernando Henrique Cardoso (Oliveira, 1995).

O desemprego, a desigualdade e a dominação são conseqüências do processo da globalização neoliberal. Podemos sentir aqui, no Brasil, a agudização dos problemas sociais há décadas sem solução. Entre todos os fenômenos e efeitos produzidos pelo neoliberalismo sentimos cotidianamente o desemprego em massa e o agravamento da desigualdade social com o empobrecimento de grande parte da população. Quanto às condições de vida da população, é certo que o Estado de bem-estar nunca conseguiu se estabelecer no Brasil, mas o que se assiste agora, com a proposta neoliberal em curso, é a uma desobrigação ainda mais evidente do Estado com as políticas sociais.

Neste contexto, como pensar a educação e, mais especificamente, a educação superior no Brasil? A operacionalização das idéias neoliberais, pressionadas pela globalização - leia-se dependência - da economia mundial, leva à necessidade, segundo seus defensores, da reforma do Estado. A desregulamentação pressupõe a saída do Estado não só do setor de produção mas também dos serviços públicos. Os direitos sociais, tratados como mercadorias, são colocados no setor de serviços, serviços com os quais o Estado vai se desobrigando. Dentre estes direitos sociais encontramse a educação e a educação superior.

A educação ocupa um papel estratégico no projeto neoliberal. De um lado, de preparação para o trabalho, garantia da formação do trabalhador sob nova base técnica: automação e multifuncionalidade. De outro lado, a consolidação da educação, inclusive a escolar, com função ideológica, de transmitir as idéias liberais. Assim o processo educativo incorpora as idéias de organização social oriundas do projeto neoliberal como a competição, o 
${ }^{4}$ Usamos aqui o termo interessada no sentido que Gramsci lhe dá para definir o papel da educação escolar. Escola interessada em formação para o trabalho, ou seja, o abandono da dimensão de formação integral, plena, formação humana.

individualismo, a busca da qualidade etc.

$\mathrm{Na}$ educação escolar, as instituições de ensino e, entre elas, as instituições de ensino superior $e$ as Universidades, têm sido alvo das reformas políticas $e$ sociais do projeto neoliberal. O Banco Mundial, organismo internacional que, junto com o BIRD e o FMI, vem impondo programas de estabilização e ajuste da economia brasileira, também tem traçado diretrizes para as políticas de ensino superior no Brasil. A meta, dentro do ideário neoliberal, é a transformação, autorizada, das universidades em empresas econômicas. Autorizada porque a política para o ensino superior pressupõe que as universidades aceitem se reorganizar em busca da qualidade e da eficiência. A estratégia dos governos tem sido o abandono das Instituições de Ensino Superior a sua própria sorte, até que, no esgotamento $e$

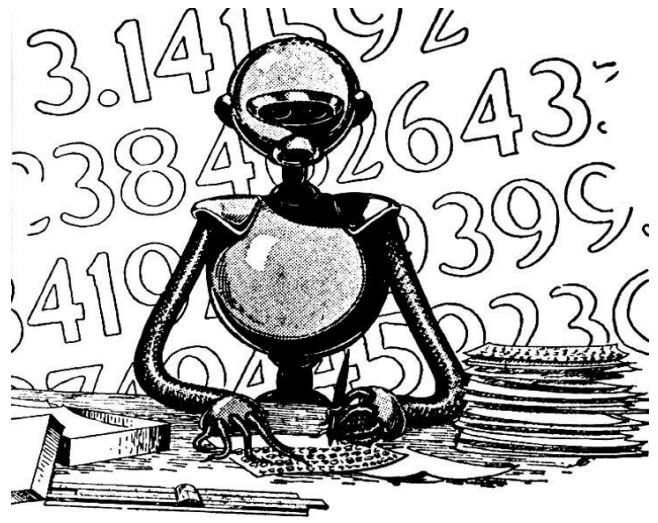

KELLY FREAS, personagem de ficção-científica, 1953 estrangulamento, elas procurem - ou seja, aceitem - soluções que, a rigor, descaracterizam sua função de produção $e$ distribuição democrática do conhecimento e, principalmente, da cultura.

As orientações gerais do Banco Mundial para a reorganização do ensino superior no Brasil, de caráter fortemente privatista, apontam principalmente, para a diferenciação institucional e a diversificação de fontes de financiamento (Sguissardi, 1998). As reformas para a educação superior não pretendem a privatização explícita das instituições de ensino superior, caracterizando uma política privatista dissimulada. Esta estratégia significa criar instituições diferenciadas de ensino superior, com tarefas diferenciadas no que diz respeito à produção e à transmissão dos conhecimentos, tarefas marcadamente interessadas ${ }^{4}$, onde a produção $e$ distribuição da cultura não têm lugar. As instituições de ensino superior, diferenciadas, perdem, nesta proposta, a articulação - a indissociabilidade entre ensino, pesquisa e extensão. Assim, teríamos instituições de ensino e instituições de pesquisa (a extensão desapareceria?) de diferentes padrões de qualidade. O que isto pode significar para a pesquisa $e$ a formação dos jovens brasileiros?

A diferenciação de fontes de financiamento significa, dentro do ideário neoliberal, a desobrigação do Estado com o financiamento das atividades das universidades públicas. A busca de fontes alternativas de financiamento põe em risco um dos princípios básicos da universidade: a autonomia. A dependência das universidades de setores diretamente inseridos no mercado numa sociedade capitalista como a nossa, pode significar alto risco para a produção, independente de conhecimentos e elaboração da cultura. As decisões sobre a pesquisa, por exemplo, passam agora a ser dirigidas segundo as necessidades do mercado. Esta reorganização do ensino superior significa, operacionalmente, a transformação das instituições de ensino superior em organizações sociais.

Do ponto de vista jurídico, organizações sociais são organizações públicas 
não estatais, de direito privado, que, mediante contratos de gestão com o poder executivo, podem fazer parte do orçamento público federal, estadual ou municipal (Sguissardi, 1998). Do ponto de vista político, as diferenças entre organização social $e$ instituição, no caso Instituições de Ensino Superior, dizem respeito a sua forma de inserção na sociedade. Enquanto uma instituição pode incorporar a idéia de construção de uma sociedade mais justa e igualitária, uma organização social tem caráter funcional, ou seja, de adaptação de suas atividades às necessidades já colocadas pela estrutura social vigente.

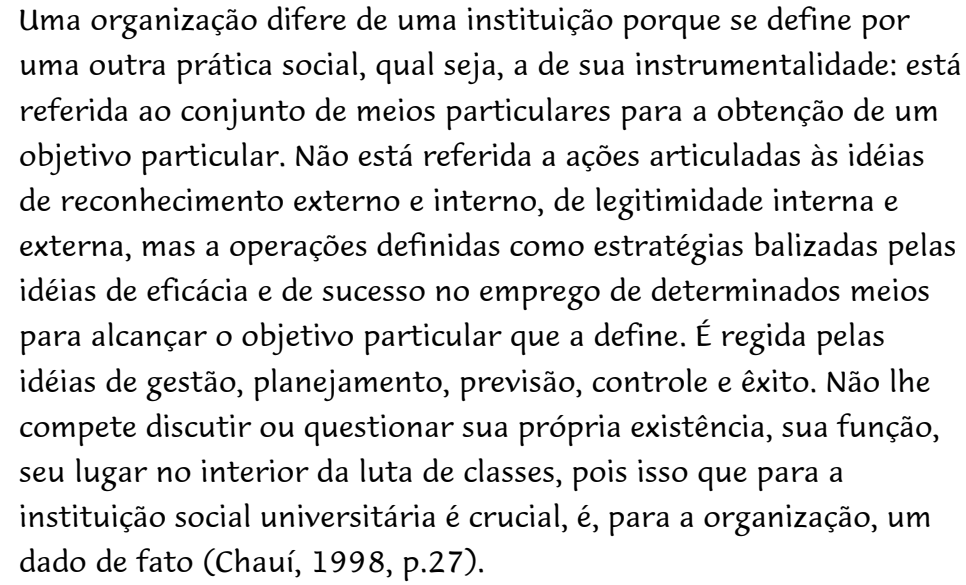

Assim, os serviços públicos de educação estão totalmente inseridos nas exigências do mercado globalizado, sob a hegemonia das idéias neoliberais. $\mathrm{O}$ tom das reformas pretendidas para a educação superior é o da eficiência $e$ racionalidade, desarticulando, com isso, as possibilidades de resistência. Como se opor a reformas que pretendem a eficiência das instituições de ensino superior? As estratégias de caráter administrativo racionalizador escondem a intenção de descaracterização das instituições de ensino superior como instituições sociais de produção autônoma e desinteressada de conhecimento e de cultura, submetendo-as às novas formas de organização do capitalismo, usando-as como mais um instrumento de controle a seu favor. Caminhamos para a transformação dessas instituições em espaços políticos sem autonomia, sem efetiva participação social e sem possibilidade de colaborar para a construção de uma sociedade mais justa $e$ igualitária.

\section{Referências bibliográficas}

ANDERSON, P. Balanço do neoliberalismo. In: SADER, E., GENTILLI, P. (Orgs). Pós-neoliberalismo: as políticas sociais e o Estado democrático. Rio de Janeiro: Paz e Terra, 1995. p.9-23.

ANTUNES, R. Adeus ao trabalho? Ensaio sobre as metamorfoses e a centralidade do mundo do trabalho. São Paulo: Cortez, 1995.

CHAUÍ, M. A Universidade hoje. Praga: Estudos Marxistas, v.6, 1998. p.23-32. 
CONY, H. O novo Holocausto. In: FORRESTER, V. O horror econômico. São Paulo: Editora da UNESP, 1997. $2^{\mathrm{a}}$ capa.

DOWBOR, L. Os novos espaços do conhecimento. 1994. (mimeog.)

HAYEK, F. A. O caminho da servidão. Rio de Janeiro: Instituto Liberal, 1990.

IANNI, O. Teorias da globalização. Rio de Janeiro: Civilização Brasileira, 1997.

KURZ, R. O torpor do capitalismo. Folha de S. Paulo. São Paulo, 11 fev. 1996. Caderno Mais! p.5-14.

LÖWY, M. Mundialização e internacionalismo: a atualidade do Manifesto Comunista. In: TOLEDO, C.N. (Org). Ensaios sobre o Manifesto Comunista. São Paulo: Xamã, 1998. p.115-25.

MARX, K., ENGELS, F. Manifesto do Partido Comunista. São Paulo: Escriba, 1968.

MORAES, M. C. M., DUAYER, M. A recelebração do mercado: repercussões nas ciências sociais e na história. 1995. (mimeog).

OLIVEIRA, F. Neoliberalismo à brasileira. In: SADER, E., GENTILLI, P. (Orgs). Pós-neoliberalismo: as políticas sociais e o Estado democrático. Rio de Janeiro: Paz e Terra, 1995. p.24-8.

SANTOS, M. A aceleração contemporânea: tempo mundo e espaço mundo. In: SANTOS, M., SOUZA, M. A., SCALARTO, F. C., ARROYO, M. (Orgs). Fim do século e Globalização. São Paulo: Hucitec, 1995. p.16-45.

SGUISSARDI, V. Políticas de Estado e de Educação Superior no Brasil: alguns sinais marcantes da dependência. In: MOROSINI, M. (Org). Mercosul/ Mercosul: políticas e ações universitárias. Campinas. Autores Associados; Porto Alegre: Editora da Universidade, 1998. p.7-40.

THERBORN, G. A crise e o futuro do capitalismo. In: SADER, E., GENTILLI, P. (Orgs). Pósneoliberalismo: as políticas sociais e o Estado democrático. Rio de Janeiro: Paz e Terra, 1995. p.39-53.

TOURAINE, A. Um mundo em pedaços, a fragmentação progressiva das zonas de influência põe em dúvida o sucesso da globalização. Folha de S. Paulo, São Paulo, 13 ago. 1995, p.5 -13.

PIRES, M. F. C.; REIS, J. R. T. Globalización, neoliberalismo y universidad: algunas consideraciones. Interface _ Comunicação, Saúde, Educação, v.3, n.4, 1999.

Este artículo presenta las principales señales del proceso de globalización y los principios básicos del proyecto neoliberal en desarrollo en el mundo actual y considera las consecuencias de la subordinación de una economía periférica a los intereses del capital internacional. El proceso de globalización de la economía y el avance de las ideas neoliberales imponen a la sociedad brasileña la transformación de los servicios públicos de educación y salud en medios de acumulación privada del capital, algunas veces de forma disimulada, en perjuicio de las condiciones de vida de la mayoria de la población.

PALABRAS-CLAVE: reforma urbana, organización \& administración, política social. 
